\title{
Factors Influencing Effective Management of NGO Partnerships
}

\author{
Rehema Batti \\ School of Management, Atlantic International University, Honolulu, USA
}

\section{Email address:}

rehemabatti2012@gmail.com

\section{To cite this article:}

Rehema Batti. Factors Influencing Effective Management of NGO Partnerships. Humanities and Social Sciences. Vol. 5, No. 5, 2017, pp. 158-170. doi: 10.11648/j.hss.20170505.11

Received: July 12, 2017; Accepted: July 25, 2017; Published: August 23, 2017

\begin{abstract}
Partnership is an emergent and dynamic process and working in collaboration with others is never easy especially when it involves organizations with diverse and sometimes conflicting mandates, cultures, capabilities and aspirations. However, local NGOs in developing countries experience difficulties in effectively achieving their mandates without collaborating with others. Effective management of partnerships is important because a failed partnership process can be disastrous and ruin an organization's viability and legitimacy. The purpose of this paper is to highlight obstacles that hinder effective management of partnerships between Local NGOs (LNGOs) and International NGOs (INGOs). The study results indicate that NGO partnerships added value to development efforts at community level however this good work may be affected if obstacles that hinder effective management of partnerships are not consistently addressed during the partnership lifecycle. The following obstacles were highlighted; minimal involvement in decision making, inadequate technical and organizational capacity, inadequate resources to support partnership objectives, minimal participation in project design, inadequate communication and low levels of commitment. In conclusion the study findings suggest that NGO partnerships still operate at a transactional level. It would be ideal if those who initiate, engage and manage these partnerships progressively shift to more transformational forms of engagement in-spite of the funding aspect.
\end{abstract}

Keywords: Partnership, Collaboration, NGOs, INGOs, Alliances

\section{Introduction}

Despite progress on the Millennium development goals (MDGs), poverty and inequality remain the central challenges in development. Both INGOs and LNGOs play a crucial role in promoting sustainable development at local, national and international level.

Partnership is increasingly interwoven into the fabric of development work. Across all sectors, attention is paid to the potential of partnerships to enhance development outputs and outcomes [1].

Partnerships are now identified as an effective and sustainable mechanism to addressing complex health and social problems facing diverse communities.

The last decade has seen a shift from short-term philanthropic relationships to more long-term and strategically focused partnerships between NGOs and both business and government $[2,3]$. NGO to NGO partnerships are also becoming more common in the development sector.
In Africa, NGOs play a crucial role of providing much needed services among communities who live in remote areas and where the other players may not easily access the areas due to poor infrastructure. The services these NGOs provide are implemented as projects at community level.

The partnership approach has emerged as one way for NGOs in the development sector to implement interventions to alleviate poverty, address inequalities in health and environmental concerns. However few NGOs have been able to effectively leverage the opportunities and benefits that partnerships offer at community level.

The MDGs have mobilized action from governments, civil society and other partners around the world, with significant results obtained through partnerships. International and local NGOs have become central in addressing and tackling issues of poverty, and they are now viewed as important within the society [4].

However, despite this growth and involvement in development local NGOs in Africa are still viewed as weak 
compared to government and corporations. NGOs are normally perceived as weak because they have inadequate funds, structures and capacity compared to the other two sectors.

Partnerships form a strong pillar in current development co-operation policy. However the current commitments to some partnership are more tokenistic in nature. They observe that partnership approaches often fail to consider issues of power in the relationship, and that the impact of power imbalances eventually impacts the development of sustainable co-operation [5].

NGO-NGO sector partnerships have become more common in the development landscape. In the past development NGOs have collaborated with other NGOs during emergency intervention projects (natural disasters) within countries. However the current preferred model puts an emphasis on jointly working with other organizations as "partners" and this has resulted in a shift in collaboration approaches.

NGOs are being pressurized to pursue partnerships with other stakeholders at community level if they are to benefit from any funding. This shift is encouraged as a way of helping NGOs and other stakeholders leverage resources like expertise, funds and knowledge available at community level thus enhancing sustainability of development efforts.

Partnerships provide an opportunity and resources for both local and international NGOs to identify and implement integrated strategies that strengthen development initiatives at regional and community level.

Building collaborative partnerships between local and international organizations will be realized when NGOs realize that both their interests are served in partnerships. In addition for the partnerships to be maintained they will require committed resources, changes in behaviour and quality leadership [6].

Well-planned partnerships are one of the best mechanisms for improving the quality and co-ordination of services, particularly to vulnerable individuals whose needs might otherwise be neglected [7].

\section{Overview of Partnerships in Development Work}

Globalization has given rise to the significance of NGOs involvement in development intervention across many continents and nations.

"Partnerships involve two or more organizations entering a collaborative arrangement based on: (1) synergistic goals and opportunities that address particular issues that single organizations cannot accomplish on their own; and (2) whose individual organizations cannot purchase the appropriate resources or competencies through a market transaction [8]".

Partnership "is a relationship where two or more parties, having common and compatible goals, agree to work together for a particular purpose and/or for some period of time" [9].

Development NGOs have realized that they cannot achieve their mandates by working alone. Community needs continue to be numerous and society's problems are too dynamic to be handled by a single organization.

NGOs should not be viewed as islands and their performance is impacted by relationships and collaborations with other development stakeholders [10].

Local NGOs (LNGOs) need resources to help them continue providing services to the community and they have for a long time relied on the generosity of donors to support their project activities through grants and donations [11].

On the other hand, international NGOs (INGOs) have realized that for project interventions to be a success they need to work with entities that are familiar with the local contexts and as such provide a link to reach out to the most vulnerable communities. The utilization of local knowledge and structure has been identified as one way of addressing issues of sustainability.

Partnerships often have significant benefits and they are a response to the complex and multifaceted problems that face society, that cannot be tackled effectively by an individual entity alone [12].

While it has been realized that local and international NGOs partnerships are crucial in addressing development needs in the communities there are concerns that some partnerships approaches and engagements are disempowering.

Many development projects in Africa use a "partnership" approach between a local NGO and an international NGO. The International NGO (INGO) normally supports projects through funding, provision of technical advice and many at times guides how the project will be managed while the Local NGO (LNGO) plays the role of implementing projects at community or country level.

This interaction between the LNGO and INGO are often perceived to be partnership, but sometimes questions arise whether this is a valid description of the relationship.

Five types of relationships that are observed between LNGOs and INGOs [13];

a) Partner

A true partnership exhibits full, mutual support for the identity and all aspects of the work and the well-being of each organisation. It is holistic and comprehensive, with no limits in principle as to what the relationship would embrace. This type of interaction is not common.

b) Institutional Supporter

This type of relationship is mainly focused on the overall development effectiveness and organizational viability. It focuses on policies, strategies, operations, management, organizational sustainability, sectoral relations and so on. In other words, transactions benefit both what the organisations do and what they are.

c) Programme Supporter

This type of relationship focuses on a particular area of development work. This focus is understood in terms of sectors, such as health or education, small-scale enterprise, human rights among others. Support could be financial inputs, technical expertise, facilitating access to specialist networks and others

d) Project Funder 
The relationship is narrow and focused. It revolves around negotiation on discrete projects. It can include the fine detail of design, implementation, monitoring, and evaluation and so on. This type of relationship can result from an organization gaining funds for an initiative that it identifies. It can also arise from winning bids for development initiatives which others want to have implemented.

e) Development Ally

In this relationship two (or more) organisations agree on a development agenda or objective they wish to pursue together, typically for an agreed period of time. They can do this, for example, by exchanging information, sharing expertise or employing their respective positions and contacts in coordinated ways. However, while modest financial transfers may occur, they are not the basis of the relationship.

"The overuse of the word "partnership" in development has become virtually meaningless and discredited [14]". The issue of power imbalance in partnerships has been observed and continues to be a big challenge that impacts on many local and international partnerships' reputation and credibility.

Yet many partnerships continue to ignore this aspect and unfortunately this leads to development of structures that may allow the partnership to function but the partnerships are perceived as 'relationships of convenience between unequals rather than 'real partnerships' [15].

Resources largely determine partnership engagements and its effectiveness. It has also being noted that the one-way flow of funds from INGOs to LNGOs has led to unequal power structures in North-South NGO partnerships [16, 17, $18,19,20]$.

There is now a deliberate shift in the development approaches of INGOs to collaborate with LNGOs as partners rather than as contractors. This has resulted in changes in some INGO partnerships structures and practices that had been for a long time viewed as unresponsive and controlling by LNGOs in many countries.

However some partnerships still exist on an uneven playing field, with the partner controlling finances often determining the terms of the partnership [21].

Even though the concept of partnership refers to something beyond the simple transfer of money, in practice many partnerships between international and local NGOs remain one-way funding streams, despite the fact that they are often called partnerships.

The term partnership is sometimes used to conceal the unhealthy nature of many aid-related relationships; that are characterized by imbalances, dependency creating and based on skewed compromise. Such relationships result to disempowering NGOs receiving the aid [22].

Nonetheless, it is necessary to note that partnership is not a neutral term and partnerships which are poorly conceptualized and badly managed end up promoting dependency, ultimately doing more harm than good [23].

NGO reliance on the programmatic and geographic priorities and definitions of poverty of donors means that NGOs do not hold, as commonly perceived, strong comparative advantages in grassroots-driven development
[24].

NGOs project interventions often align to donor priorities and this is because many NGOs have inadequate skills and experience for designing programmatic interventions that reflect the needs of the communities they serve.

Even though LNGOs have a desire to work in partnership, but how to do this effectively with sustainable results remains a challenge. Despite all the collaboration, the achievement of the missions of these organizations is sometimes not realized. This results to lack of impact at community level and disillusionment among the local NGOs.

The formation of NGO partnerships should be a systematic and well planned process that takes into account the strategic directions of the organisations rather than an adhoc venture [25].

Many partnerships operating in developing countries fail to live up to the concept of an ideal partnership because most of them currently operate at a transactional level. In such a relationship the principles of partnerships and relationship management practices are often overlooked or ignored.

Partnership principles (equity, transparency and mutual benefits) may seem obvious but they are easily overlooked especially when partners begin to take each other for granted and relegate to second place relationship management over the partnership's project (s) or their individual organizational priorities [26].

There has been an increasing concern that NGOs partnerships are failing to achieve the sustainable impact as expected and many have minimal influence at local community or regional levels. Partnerships including those operating at the grass roots level while desiring to extend their activities should also focus on expanding their influence [27].

Partners were observed to have different perspectives and understanding of what partnerships entail and the role of the entities involved [28].

Partnerships can increase their influence and impact when there is a shared understanding of what true partnerships entail and how each partner contributes to the actual practice of partnering.

According to some scholars [29] the failure rate among alliances is often reported to exceed sixty per cent $(60 \%)$ while others [30] observed that partnerships had a failure rate, as high as fifty per cent $(50 \%)$. These statistics imply that millions of dollars and resources are wasted or lost when partnership engagements fail. It also means that many organizations' reputation and image are destroyed as a result of these failures.

It is crucial that partnerships succeed because evidence of partnership working is a pre-condition for organizations to access diverse sources of funding [31].

Partners are different and diverse and not all will view the partnership as a priority. Therefore, it is unfair to assume that people and institutions are universally ready and waiting to be engaged in the process [32].

Development work at community level will change as collaborative partnerships are developed. There is a greater need for mutual partnerships between local and international 
NGOs at community level [33].

It is crucial for both local and international NGOs in developing nations to explore and understand limitations or barriers that affect partnerships and develop more comprehensive approaches to ensure their impact and sustainability. Partnering is about achieving results collaboratively [34]. Participatory development is envisioned to be possible when NGOs from the North and South understand reciprocal forms of collaboration [35].

Justification and Objective of the Study

Partnerships have been identified as a key mechanism to achieve more coordinated services, to address service gaps and to pool resources to meet the needs of those accessing services [36].

NGO-NGO partnerships are notable in delivering services at community level and therefore ensuring partnership success is crucial in the development sector.

"Effective partnerships will help resolve a number of challenges, including the fragmentary nature of activities and the duplication of initiatives that characterize the situation in many countries [37]".

Management of partnerships is an aspect that falls in the second phase of the partnership cycle and if this phase is not well negotiated then partners' experience frustration, commitment levels diminish and finally the partners lose interest in the partnership.

"Setting up a partnership is an important step but to keep it going is just as complicated, and ongoing attention has to be maintained [38]".

Much of the literature that exists on NGO partnerships concentrates almost exclusively on defining types of partnership and identifying ideal principles for effective partner relationships [39]. Generally there is a minimal academic research that highlights factors that aid or hinder effective partnership management from the perspective of LNGOs in the African continent.

Existing literature on partnership focuses on types of relationship and defining models [40]. There is little discussion about current practice and very few case studies.

There is limited partnership research focusing on the community sector hence reinforcing a "need for local studies in developing an understanding of merger and other forms of strategic restructuring, rather than relying on the international and/or private-sector literature [41]".

The study targeted NGOs involved in LNGO-INGO collaborations and those who implement development projects in rural and remote areas.

A partnership comprises of close interaction between organisations and beyond their relational nature there is an underlying question of how partnerships are managed internally by the parties concerned [42]. The answer to this question is key because how partnerships are managed has an impact on the performance and reputation of the NGOs involved. This study sought to highlight aspects that affect the management of the partnerships.

It has been observed that the management of partnerships also affects NGO effectiveness and efficiency [43].
Many international NGOs have resulted to adopting a partnership approach as a development model to facilitate service delivery within selected regions and communities. However, there has been little empirical research on how NGOs implement partnerships in practice and the challenges they face in developing and managing effective partnerships [44]. The study therefore, sought to identify obstacles that were perceived to affect effective management of partnership between local and international NGOs.

The study used both qualitative and quantitative research methods to collect information from NGOs that have experience working in NGO partnerships at community level.

\section{Study Findings and Observations}

The study revealed that partnerships between LNGOs and INGOs are beneficial. The local NGOs perceive themselves as implementers and the international NGOs as funders. This view may be due to the current structure and nature of the partnerships that the NGOs engage in.

The study identified the following obstacles that were perceived to affect partnership management; $52 \%$ of the respondents identified minimal involvement in decision-making, $40 \%$ identified inadequate resources to support partnership objectives, $36 \%$ of the respondents identified minimal participation in project design and inadequate technical and organizational capacity, while $32 \%$ identified low levels of commitment and inadequate communication respectively. (See fig 1 below)

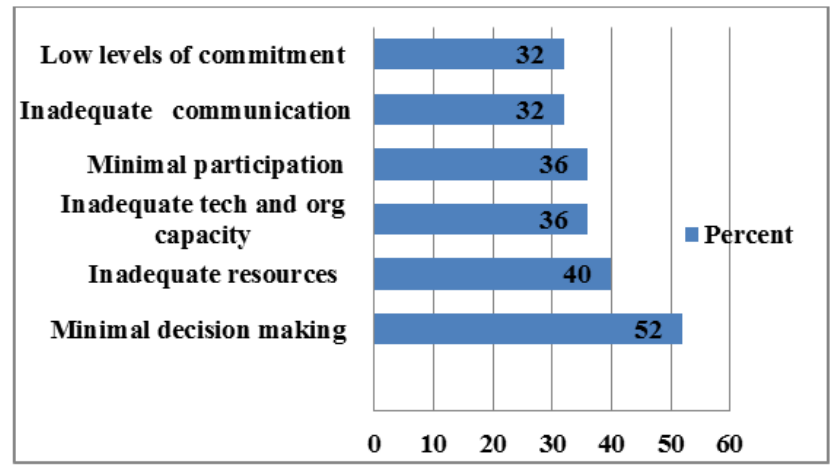

Figure 1. Obstacles affecting NGO Partnerships Management.

The following is a summary discussion of the obstacles identified in the study;

\subsection{Minimal Involvement in Decision Making}

Minimal involvement in decision making was seen as the major contributing factor that acted as a barrier in partnerships. Shared decision making is an important factor within partnerships but the most difficult aspect to realize.

Involvement in decision-making appears to be an incentive for operators to perform better. However, partnerships tend to involve NGOs through contracts as implementers or service providers [45]. This could be one reason that explains the lack or inadequate involvement in decision making processes.

Sometimes due to frequent reorganizations within 
organizations and the partnerships, those individuals accountable for achieving the results are not adequately involved in the decision making process.

Minimal involvement occurred when individuals or organizations who were perceived to have more power and influence ignored any contribution from others. In other instances, feedback from individuals with expertise was ignored or overlooked when making certain decisions in favor of those who seemed influential.

Another reason that could have resulted, in organizations minimal involvement could be attributed to inadequate capacity of the organization or the capacity of those who represent the organizations during the decision making process. This argument is supported by scholars [46] who argue that while partners' ability to influence decisions is affected by the institutional rules, some have more influence than others depending on their organizational capacity and their respective project-officers.

Reason for minimal involvement could also be due to inefficient mechanisms to guide the decision making processes within the partnership. It is important to have protocols for decision-making and anticipated types of decisions; types of decision making roles; who is responsible for making sure decisions are made and how to resolve challenges arising from lack of implementation of decisions made [47].

Minimal involvement in decision making results in: exclusion of some partners; disempowerment of organizations; lack of alignment between project interventions and resources; increase in execution risk; feelings of betrayal; high levels of mistrust; minimal consensus on how tasks are to be undertaken; organizations feeling exploited; partnerships are perceived to be insensitive to NGO's expectations or unique abilities; weakening of organizational structures; and the lead agency is perceived to have greater control of the decision making process.

Many partnerships are unable to effectively distinguish between strategic and operational level decision making processes. This eventually causes confusion, ambiguity and misconceptions on the roles partners play in the decision making process.

Equality of decision-making and mutual influence are key characteristics distinguishing partnership from other types of relationship. Yet, in practice, developing a relationship characterized by a free and equal exchange of ideas is challenging [48].

\subsection{Inadequate Resources to Support Partnership Objectives}

Many local NGOs pointed to the fact that resources set aside to achieve the partnership objectives were often insufficient to support the interventions required at community level. This meant that some partnership objectives and initiatives were difficult to undertake based on the resources allocated.

Inadequate resources to support partnership objectives implies: diversification of interventions becomes complicated; partners fail to deliver what was envisioned; partnership lacks operational flexibility; reduced partner commitment; unhealthy competition among partners; negative publicity; partnership's integrity is compromised and the loss of momentum towards achievement of partnership outcomes. In the end the partnership responsiveness and effectiveness is affected.

Unfortunately, initiators and collaborators within the NGO partnerships often assume that the same amount and type of resources can be used consistently throughout the partnership lifecycle. This assumption leads to allocation of inadequate resources to sustain the partnership outcomes.

The findings are consistent with development studies carried in other countries. Partnerships between Northern and Southern NGOs were observed to develop around project funding systems. Organisational structures reflected the needs of the funding, monitoring and evaluation systems; rarely were they developed around the needs of a specific partnership [49].

\subsection{Inadequate Technical and Organizational Capacity}

A challenge limiting achievement of full partnership potential currently is linked to the partner organizations' weak and inadequate administrative procedures and practices.

"Many organizations in the independent sector, especially smaller groups or recently founded institutions, continue to neglect building organizational capacity in favour of developing and implementing programs [50]".

Organizational limitations experienced at partner level impact on a partnership's performance. The lack of structures contributes to obstacles such as: difficulties in attracting and retaining a diverse membership, lack of accountability among partners, dependence of the group on a small handful of core leaders, and communication challenges at partnership level [51].

NGOs tend to invest less in building the technical capacity of their staff and put more emphasis on programme implementation and meeting deadlines. As a result of this the quality of services and programs implemented is compromised and collaborations are undermined [52].

Inadequate capacity at organizational level results in; formation of overly bureaucratic; inadequate resources; no clear division of labor; development of unsustainable interventions; inadequate accountability structures; cumbersome decision making processes; increased exposure to compliance related risks; inadequate governance structures and organizational inertia.

Despite the fact that local NGOs based in the rural areas played an important role in natural resource development, their effectiveness was constrained by technical and specifically by organizational limitations [53].

Inadequate capacity at organizational level affects NGOs' ability to consistently achieve the partnership objectives. The lack of technical and organizational capacity causes many partnerships to; lose their competitive advantage and credibility, have an unstable resource base, partnership outcomes are not consistently sustained and they fail to 
leverage on emerging opportunities in their sectors.

\subsection{Minimal Participation in Project Design}

Active participation of organizations during the project design phases is important.

Ideally, it is during the initial design phase that the magnitude of the problem is identified, objectives and options are explored to develop the most appropriate model. However in many partnerships, there is minimal or an absence of NGOs involvement in the area of project design.

Sometimes the partnership involves the wrong stakeholders or excludes others during the project design. This results in the development of project interventions that do not reflect the context and magnitude of need at the community level.

Low and non-participation of partners could be because they are intimidated, have lost interest, incapable or disenfranchised [54]. Minimal participation in the project design could be because the partnership lead (initiator) lacks capacity and knowledge in participatory and engagement approaches.

Unfortunately, many partnerships end up missing an oppurtunity for identifying and exploring complex interactions that may eventually affect the performance of the partnership.

Project design process involves identification of the objectives, deliverables, resources, determination of the criteria for success and key implementation aspects of the project.

However, in some scenarios the project objectives or structure are determined at national or donor level. In such instances it is difficult for other stakeholders within the partnership to contribute their feedback on the proposed project model.

Minimal involvement of partners in project design leads to; inadequate analysis of local context; projects tend to be more activity focused; diversification of interventions becomes difficult; increase in project costs; misaligned partner interests, projects are more donor driven and do not address the local needs; project outcomes are difficult to verify and leveraging on local resources becomes an uphill task. This affects the viability and sustainability of projects initiated by the partnerships.

It is critical that all partners perceive that their involvement in the partnership work is worthwhile or else those who feel they are placed on the margins will become disengaged. If this happens, the potential benefits of partnership will be difficult to achieve [55].

\subsection{Inadequate Communication}

When communication is not effective it affects meaningful dialogue and interactions among the organizations involved. Inadequate communication causes mistrust and suspicion among the partners and creates challenges in many partnerships. Many unfulfilling relationships are as a result of inadequate communication between individuals and organizations [56].
Unfortunately in some partnerships communication is skewed to a few people mostly those who appear to talk the most or those perceived to be influential in their organizations.

Poor communication has been noted as a significant challenge in partnership work [57]. The frequency of communication and type of communication channels used was observed to affect effective communication among the partners.

Inadequate communication in partnerships results to; conflicting information about what the partnership does, duplication of roles and activities among partners; increase in collaboration risk; less productive relationships; minimal learning or knowledge sharing; low team cohesion; failure to effectively leverage internal expertise and knowledge and an increase in organizational conflicts.

Limited opportunities or mechanisms for information sharing or feedback results to organizations being excluded from some partnership initiatives. In the long run the achievement of the partnership goals is affected.

"Effective and continuous communication between partners is fundamental to the partnership moving forward and to ensuring it achieves the envisioned goals [58]".

\subsection{Low Levels of Commitment}

Inadequate commitment among partner NGOs in the partnerships is a recurring challenge. Conflicting priorities between those of the partnership and respective organizations sometimes resulted to low commitment levels [59].

In many partnerships there is limited buy-in from the partner organizations beyond the contractual agreement. There are situations whereby NGOs are involved in networks because of either the funding agency or the NGO head quarter request or pressure. This creates a lack of commitment to the partnership objectives by some of the organizations [60].

Low levels of commitment could be caused by a lack of a shared vision, values of the partners are incompatible, inadequate resources to support objectives, inadequate or lack of commitment at senior management level, failure of organizations to undertake what they promised, failure to adhere to agreed norms and changes in organizational priorities or leadership.

Commitments are often made at organisational level but it is an individual who fulfills them. If the individual fails to understand what is expected to achieve the objectives or perceives there is no added value in undertaking the task then the individual's level of commitment declines.

Partnerships between INGOs and LNGOs are sometimes formed on an ad-hoc basis and therefore end up engaging with organizations whose mandates or interests are not aligned to the partnership objectives. Unfortunately, this means that execution of the partnership objectives is given less emphasis at organizational level.

Low levels of commitment results in poor performance among the partners, minimal ownership of partnership outcomes, low levels of trust, minimal value creation, less participation in decision making processes and minimal strategic or operational integration. 
When commitment or interest shifts it means the partnership is likely to consistently under-perform, lose credibility or resources and finally fails to achieve its goals. Partnerships are perceived as mere dialogues until those involved make a tangible commitment to the collaboration process [61].

\section{Recommendations}

Partnerships are not easy, and attempts to establish effective partnership mechanisms face a range of cultural, political economic and social barriers. There is always a risk when more emphasis is on the funding and this often skews the partnership to a more transactional relationship.

Partnerships between local NGOs and international NGOs are important in undertaking development interventions at community level. It is critical that they are well structured and managed for them to be effective and legitimate.

Partnerships between NGOs have both an organizational and a relational dimension [62]. These two aspects have to be considered when developing interventions and strategies to manage the partnership operations and outcomes.

The potential impact of NGOs and development operations can be high but actual impact is dependent on overcoming the numerous obstacles that hinder effective partnership [63]. The following recommendations can help minimize the obstacles highlighted.

\subsection{Develop Responsive Partnership Structures}

Many partnerships face challenges because the structure, operations and processes that exist within the partnerships are underdeveloped or obsolete.

Partnerships are dynamic and evolve overtime and it is crucial that processes and systems are modified or developed that enhance the NGOs' and partnership performance.

Often during the course of the partnership external or internal changes occur that may require adjustments or modification to partnerships objectives, structures, strategies, stakeholders' roles and management processes.

It is crucial that NGOs understand that all partnerships evolve and have phases of growth. This situation often results to some modification of operations, interventions and systems of partner organizations or the partnership itself.

Structures and processes that are weak or inadequate tend to hinder the achievement of the partnership mandates and effectiveness of its operations. There is a great need to develop procedural and substantive process that will contribute to organizational compatibility and interaction value [64].

The process of collaboration has been observed to have a 'natural' path from infancy through adolescence into maturity and closure. This process can be expedited, but seldom circumvented without damage [65].

Utilizing the partnership lifecycle approach is one way of assisting partnerships develop responsive structures and systems.

The lifecycle approach entails sub-dividing the partnership development into well-defined phases and taking into account expected changes that are likely to be encountered from one phase to another. This enables management to restructure the partnership at the opportune time or initiate a transition.

Looking at a partnership in different stages is a useful model because at each stage there are different tasks and priorities that need attention. The lifecycle approach helps to navigate implementation and anticipate certain behaviors among the partners and identify issues that are important during each stage [66].

In each partnership phase there is a continuous interaction between project interventions, values, norms, stakeholders' interactions, leadership and processes. It is imperative that these aspects are monitored and aligned to the partnership objectives and outcomes envisioned.

Once a collaborative partnership has been initiated changes will occur. As the relationship grows it will necessitate changes among the NGOs involved [67]. Aligning partner organizational systems to partnership governance structures is crucial but in many cases it is an aspect that is often overlooked or ignored in many partnerships.

Due to partnerships dynamic, changing and evolutionary nature, governance evolves over the partnership lifecycle rather than implemented from the beginning [68]. It is imperative that a partnership develops a comprehensive framework that guides its operations and management.

Good governance enables organizations to respond effectively to changing situations and follow through on commitments and strategic plans [69].

Even at an early stage, partnerships need to have governance structures in place to ensure that decision-making, management and development arrangements are appropriate and operate effectively [70].

Partnerships should periodically assess the extent to which the partnership operations and management processes meet the partnership and organization growth needs. Partnerships need to remove or revise processes that are outdated or non-productive.

The main task of partnerships is "to explore ways in which organisations with their different tasks, responsibilities and approaches can cooperate in dynamic societies. It is necessary for the partnerships to adapt methods and ways of working accordingly [71]". When partners share a basic understanding of what partnering entails, governance is easier [72].

Organizations with a reputation of being good partners have well documented partnership processes and additionally these processes have been institutionalized [73].

Presence of responsive structures and practices guarantees that synergistic partnerships continue long after their initiators have transitioned from the engagements.

\subsection{Nurture Empowering Relationships at Organizational Level}

"Relationships are the foundation of partnerships. Successful partnerships are managed by individuals who recognize the importance and benefit of cultivating healthy working relationships" [74].

Many partnerships fail in the area of relationships compared 
to implementation of plans or financial compliance. A lack of trust and inadequate communication has been noted to contribute to many relationship failures.

Very few partnerships seek to examine the working relationships among partners and the link between process and performance. Most partnerships emphasize a contractual focus and rely more on the contracts developed and overlook the relational aspect of the partnership [75].

Relations within partnerships involve the individuals and organizations spearheading the partnerships. Therefore, there is a need to manage relationships in such engagements [76].

Partnerships should focus more on building relations at organizational level. Many partnerships often rely more on individual level relations and overlook the organizational aspect hence the partnership in the long run does not receive organization wide support. A balance is required concerning the two aspects.

Partnerships need to develop more interactions at inter-organisational level, and not just focus on individual or department levels. There is a need to broaden the inter-organisational dialogue [77].

Partnerships require the development of strong relational skills to foster trust, inclusiveness, respect and openness among partners. Successful partnerships are characterized by strong empowering relationships.

Partnerships are about balancing business and relationships unfortunately sometimes the project or donor priorities easily overshadow relationships. Partnerships that envision creating meaningful engagements that yield high value will require the organizations and individuals involved in the partnerships to be competent in the art and science of relationships [78].

Partnerships must analyze the impact of power dynamics and behaviour of one group on the actions of others. This is crucial because some NGOs join partnerships with misconceptions on how a partnership should be or how it should be managed. Other organizations have developed an attitude of "this is how we have done it", because of previous successful partnerships. All these attitudes and misconceptions create obstacles in introducing more innovative approaches to partnerships engagements.

"Ideally, an autonomous organisation is able to maintain horizontal relations with other actors as equals [79]".

Relationships within partnerships can be strengthened through development of clear partnership norms that support collaborative behavior and practices. It is important that everyone understands and agrees to uphold the partnership principles and practices that foster trust, respect, continuous learning, consensus building, shared leadership, effective communication, accountability and minimize power imbalances. This will in turn facilitate the co-creation of both social and economic value within the partnership.

Leaders are crucial in building empowering relations within each organization. The most successful partnerships have the involvement and commitment of senior management, which ensures the partnership objectives or outcomes become part of the organization's overall strategy [80].

Leaders must be accountable and encourage a partnering mindset within their organizations. This can be achieved by leaders ensuring that the partnership approach or objectives are embedded in their respective organization's strategy and operations.

Monitoring the quality of relationships among partner organizations is important and this aspect has to be embedded in the partnership governance structures.

\subsection{Align Partner Interests and Strengths for Value Creation}

Many local NGOs allude to the fact that sometimes their engagement in some partnerships results to loss of autonomy. The NGOs' priorities and missions are sometimes abandoned as more focus is on achievement of the partnership outcomes.

Local NGOs are voluntary and INGOs engaging in partnerships with them are sometimes perceived to place bureaucratic burdens or expectations on local NGOs.

What gives collaboration its focus and momentum is when it goes beyond superficial interests and taps the potential value that an entity can bring [81].

Effective management in partnerships can be strengthened through having NGOs whose interests and competencies are aligned to the partnership objectives.

Partnerships must provide mutual benefits or rewards to organizations, which corresponds to their organizational goals if they are to be sustained. If not then NGOs commitment to partnership tends to wither and this threatens the sustainability of both the project and partnership.

When "working in partnership it is important to consider how the relationship fits /interacts with the ongoing work of each partner organization and the capacity that is required of each party to make the relationship work [82]".

Partnership outcomes need to be aligned to individual organizations' overall goals and mandates. This moves partnerships and organizations from "incidental" partnerships to more to "intentional" ones. The strongest partnerships are those that have drawn together the best set of partner organization [83].

Partnerships can explore innovative ideas that facilitate organisations achieve some of their strategic objectives. However the support provided must be aligned to the overall objectives of partnership.

On the other hand, local NGOs should consider integrating some relevant partnership's aspects into their organisation's strategic plans. Partnerships become effective when local NGOs or partners become more proactive in articulating their needs and what they can offer [84].

\subsection{Ensure Availability of Strategic Resource Commitments}

Ideally each phase of the partnership requires different resource requirements and unfortunately to achieve sustainability some initiatives may require resources for an extended period of time.

Resources required to sustain partnership operations and outcomes will depend on its form, objectives, functions, duration, lifecycle phase and the sector or country it operates in. 
During the initial phase of a partnership, it is crucial that partners explore and determine the resources required to implement the agreed project or programme of work [85].

Partnerships must fit into broader systems. External resources should ideally be utilized to provide a "safety net" and should be available only for a specific period of time. External inputs and skills should add to, rather than replace, local ones [86].

This is an interesting perspective and it could be one way of ensuring that resources are available throughout the partnership period and after the formal engagement ends.

Result based planning and budgeting during each partnership phase and developing partnership resource contribution plans is important. Ideally each partner should be able to incrementally contribute towards the achievement of the partnership objectives as the partnership matures.

Performance-based long term support instead of one-off project funding is an ideal approach [87]. Partnerships should explore braided and blended funding options to support partnership outcomes and interventions.

Partnerships should consider providing additional resources for supporting innovative ideas that are aligned to the partnership objectives to stimulate and capture partners' continued interest and involvement in partnership initiatives.

Periodic reviews and evaluation of the partnership outcomes will also be key. The results of the evaluations will ensure that as the partnership expands resources and competencies are identified and adjusted to reflect the growth. This will boost the performance and viability of the partnership.

Stakeholders involved in partnerships should note that availability of resources alone will not guarantee improvement in management of partnerships but partners are required to possess competencies that facilitate partnership behaviours that help identify, mobilize and leverage the resources available.

NGOs involved in partnerships should consider including viable partnership interventions or outcomes into their long-term strategic plans.

"Genuine partnerships can be a reality when partners have the ability to bring resources to the process, or have the capability of influencing the partnership process through other mechanisms [88]".

\subsection{Boost Organizational and Technical Capacities}

Organizational structures can have a profound impact on a partnership's success. However many non-profits, focus on developing new programs and keeping administrative costs low instead of building the organizational capacity necessary to achieve their mandates effectively and efficiently [89].

Partnerships require technical, communication, problem-solving and interpersonal skills which many NGOs seem to lack as they engage in partnerships with others.

Applying and bringing the strategic partnership system to fruitation requires special skills and talents [90]. While other scholars [91] argue that certain situations may require capacity-building programs to enable affected stakeholders to participate fully and effectively in the process.

Emphasizing on partner commitment is not enough to support collaboration but in addition there is need to ensure that all organizations or individuals involved have adequate capacities to effectively contribute to the realization of the partnership outcomes.

On the other hand, INGOs should not always presume that local NGOs are ready-made implementation partners. They should facilitate capacity building strategies that would balance institutional strengthening and direct project activities.

It is imperative for a partnership to develop strategies that will focus on enhancing the capacities of local NGOs so that the organizations may gradually undertake partnership governance and management activities as the partnership matures.

When donors do not understand the partnering process and the time required to build strong and productive collaboration it creates challenges in partnership management [92].

Therefore, international NGOs need to nurture their partnership competencies to increase partnership success. Ideally both local and international NGOs involved in partnerships need to develop their respective overall organizational capacity to be effective partners.

People are often the root cause of problems and the source of solutions within partnerships. Individuals must learn the skills required to build successful partnerships [93].

Technical and organizational capacities are interlinked and it is crucial that interventions on both aspects are systematically undertaken to sustain the partnership operations.

Successful capacity building involves understanding the needs of the organisation as a whole, and how the 'bit' of capacity that is being developed contributes to its overall effectiveness [94].

\subsection{Diversify Partner Engagement Mechanisms}

Participation within the partnerships requires the involvement of individuals or organizations at various stages with the aim of building consensus and mobilizing resources to support the achievement of the partnership outcomes or project goals.

Partners quickly become disengaged, disinterested and demotivated if they perceive their contributions are disregarded or that certain individuals or organizations are frequently consulted or actively involved in certain partnership activities.

Stakeholder participation is important in any partnership engagement. The foundation of effective partnerships lies in the involvement of individuals, agencies, and organizations [95].

NGO partnerships need to undertake a stakeholder mapping and analysis exercise to prioritize the NGOs, understand their expectations, level of influence and their interest regarding the partnership objectives and initiatives. The analysis will help determine the appropriate expected roles and participation levels for each organization within the partnership. 
Partnerships need to define the levels, forms of participation and type of stakeholders to be engaged during each partnership phase. The aim is to create strategic opportunities for interactions and dialogues that meet the partner's expectation and builds political goodwill.

NGOs in partnerships can jointly identify key areas for involvement through developing participation road maps. The maps will state when, who needs to participate, at what level and with what resources during each partnership phase.

Partnerships should provide opportunities for involvement of both formal and informal leaders who are committed to the partnership to lead in selected partnership efforts.

Appropriate and ongoing partner participation is crucial as it helps the partnership monitor the impact of its operations and initiatives at individual $\mathrm{NGO}$ and community level.

A useful approach to assessing the levels of engagement is through utilizing the collaboration continuum tool. Partnerships should periodically assess the levels of engagement and explore ways of addressing any shortcomings observed [96]. When partnerships develop effective strategies for engagement they minimize occurrence of reputational and financial risks.

A partnership flourishes when it establishes systematic mechanisms and procedures for monitoring the developed participation strategies and reviews their effectiveness during each phase or when necessary.

Partnerships are open systems and their operations are sometimes affected by the actions and expectations of external stakeholders. "A partnership can manage its reputation by communicating and building good relationships with all its stakeholders [97]".

The mandate and operations of the partnership must therefore be understood and recognized by the relevant authorities and other stakeholders at the national and community level.

Those involved in partnerships should understand and appreciate that it may be difficult to consistently achieve equitable levels of participation or contribution during the course of engagement. However deliberate efforts have to be made to ensure that appropriate stakeholders are effectively involved in the partnership process.

\section{Conclusion}

Many NGO partnerships currently face challenges in identifying and managing expectations, opportunities and risks that emerge as a result of the engagement. Unfortunately, unsuccessful partnerships destroy an organization's and partnerships' reputation and credibility.

The study revealed that local NGOs still perceive themselves as implementers and the INGO as the funder. This view suggests that NGO development partnerships still operate at a transactional level.

It would be ideal if those who initiate, engage and manage NGO partnerships progressively shift to more empowering forms of engagement. This is important to address the issue of power imbalances that has been observed by many scholars to affect partnerships and secondly the change will help shift the local NGOs to more proactive roles within such partnerships.

In addition, the study findings suggest that mechanisms focusing on building effective partner relationships are still not well developed in the partnerships. Secondly, the practices of evaluating the functioning of the partnership and learning are not widely embedded in the management process of the partnerships.

It is important that initiators of NGO partnerships are not too caught up in their past or current successes so that the acheivements become a barrier that hinders them from exploring more innovative ways of making partnerships work. Those who engage in NGO partnerships need to be more proactive in exploring innovative ways that facilitate development of more empowering partnerships. The recommendations proposed will assist NGO partnerships gradually shift from transactional to more transformational partnership models.

\section{References}

[1] Hollow David (2011) An academic review of the evaluation of partnerships in development. IDRC Donor Partnership Division IDRC project number: RSP 106738.

http://idl-bnc.idrc.ca/dspace/bitstream/10625/52427/1/IDL-52 427.pdf.

[2] Brandstetter, etal, (2006) Successful partnerships: A guide. OECD LEED forum

http://www.fonduri-ue.ro/posdru/images/downdocs/brosura $p$ arteneriate_de_succes.pdf.

[3] Seitanidi May \& Crane Michael, (2014) Social partnerships and responsible business. A research handbook. New York. Routledge.

[4] United Nations Development Programme (2010) Assessing Progress in Africa toward the Millennium Development Goals. http://passthrough.fwnotify.net/download/600354/http://www.u ndp.org/content/dam/undp/library/MDG/english/MDG\%20Regi onal\%20Reports $/ 2010 \% 20$ Regional\%20Report $\% 20$ Africa.pdf.

[5] Fiona Bailey \& Anne M. Dolan (2011) the Meaning of Partnership in Development: Lessons for Development Education. Policy and practice. A development education review. Issue 13. Centre for Global education.

[6] Johnson Scott and Ludema James, (1997) Partnering to build and measure organizational capacity. Lessons from NGOs Around the World. Grand Rapids, USA. Christian Reformed World Relief Committee.

[7] Audit Commission (1998) A fruitful partnership: effective partnership working. Audit Commission

http://archive.auditcommission.gov.uk/auditcommission/siteco llectiondocments/AuditCommissionReports/NationalStudies/f ruitfulpartnership.pdf.

[8] Zadek, Simon, and Sasha Radovich, (2006.) "Governing Collaborative Governance: Enhancing Development Outcomes by Improving Partnership Governance and Accountability." AccountAbility and the Corporate Social Responsibility Initiative, Working Paper No. 23. Cambridge, MA: John F. Kennedy School of Government, Harvard University. http://www.zadek.net/wpcontent/uploads/2011/04/Havard_Go verning_Collaborative_Governance_April2006.pdf 
[9] Spigelman Martin \& Simces Zena, (2001) The Partnership Toolkit: Tools for Building and Sustaining partnerships. Collaboration Roundtable http://www.pcrs.ca/uploads/7L/_A/7L_ATXdmJl3bp9lgOtVT $\mathrm{KA} /$ partnershiptoolkit.pdf

[10] Fowler, A, (1998) Authentic NGDO Partnerships in the New Policy Agenda for International Aid: Dead End or Light Ahead? Development and Change. Vol. 29.

[11] Batti Rehema C, Challenges Facing Local NGOs in Resource Mobilization, Humanities and Social Sciences. Vol. 2, No. 3, 2014, pp. 57-64. doi: 10.11648/j.hss.20140203.12

[12] Audit Commission (2005) Governing partnership: Bridging the accountability gap. http://informationsharing.co.uk/wp-content/uploads/2012/08/ Audit-commission-governing-partnerships.pdf

[13] Fowler, Alan (2000) Partnership: Negotiating Relationships. A Resource for Non-Governmental Organisations, Occasional Paper Series No. 32, Oxford: INTRAC. http://cercle.lu/download/partenariats/INTRACPartnershipneg ociatingrelationship.pdf

[14] ibid.

[15] Horton Douglas, Prain, Gordon and Thiel, Graham (2009) "Perspectives on Partnership: A Literature Review", DFID Social Sciences Working paper. No 2009-3. International Potato center (CIP), Peru.

http://cipotato.org/wp-content/uploads/2014/08/004982.pdf

[16] Ashman, D, (2001), Strengthening North-South partnerships. Nonprofit and Voluntary Sector Quarterly. 30(1). 74-98. Civil society collaboration with business: bringing empowerment back in. World Development. 29(7) 1097-1113.

[17] Transform Africa (2004) Transforming Partnerships: The dynamics of North-South partnerships between development NGOs. London: Transform Africa.

[18] Hoksbergen, Roland. (2005). Building Civil Society through Partnership: Lessons from a Case Study of the Christian Reformed World Relief Committee. Development in Practice 15(1): 16-27.

http://policy-practice.oxfam.org.uk/publications/building-civil -society-through-partnership-lessons-from-a-case-study-of-the -chr-130696

[19] Malavisi, Anna, (2010) A Critical Analysis of the Relationship between Southern Non-governmental Organization and Northern Non-government Organizations in Bolivia. Journal of Global Ethics 6(1): 45-56.

[20] Aburi, Nancy, Wimber, Thomas and Makau, Winnie (2010) Partnership in Practice: a Kenyan Perspective on the Nature of Relationships with Irish NGOs. The Irish Association of Non-Governmental Development Organizations (Dóchas).

[21] Dolan \& Fiona (2011).

[22] Fowler (2000).

[23] Dolan and Fiona 2011: 34

[24] Banks Nicola \& Hulme David (2012) The role of NGOs and Civil Society in development and poverty reduction. BWPI working paper 171. University of Manchester. Brooks World Poverty Institute.

[25] Kukundakwe R, Arthur S, Turyahebwa A, Tindyebwa W, Byamukama E, (2013) NGO performance through NGO partnership in Uganda. International Journal of Engineering Research and Technology. Vol 2: Issue 2. Feb 2013.

[26] Halper Eva, (2009) Moving on. Effective management for partnership transitions, transformations and exits. The Russell Press.

http://c.ymcdn.com/sites/www.gbsnonline.org/resouce/collecti on/6623F089-321E-4C3B-B859-5408F4F46045/MovingOnTo olbook.pdf

[27] Halper (2009) Pg. 16.

[28] Aburi, etal (2010).

[29] Spekman Robert \& Issabella Lynn and MacAvoy Thomas, (2000) Alliance competence: Maximizing the value of your partnerships. New York. John Wiley \&Sons Inc.

[30] Corbin, J. Hope and Mittelmark, B. Maurice and Lie, Th. Gro. (2012). Scaling-up and Rooting Down: A Case Study of North-South Partnerships for Health from Tanzania. Global Health Action 5 (Suppl)

http://www.globalhealthaction.net/index.php/gha/article/view/ 18369

[31] Audit commission (1998).

[32] Steenburgen Ger and Walid El Ansari (2003) The power of partnerships. Geneva. www.who.int/management/powerpartnership.pdf

[33] Johnson and Ludema, (1997).

[34] Spekman, Isabella and MacAvoy (2000).

[35] Johnson and Ludema (1997).

[36] Pope J and Jolly P (2008) Working in partnership: practical Advice for running effective partnerships, Department of planning and Community development, Melbourne Australia http://www.vcoss.org.au/documents/VCOSS\%20docs/HSPIC/ 00911_vcoss_partner_guide_1_WEB.pdf

[37] Steenburgen and Walid A (2003).

[38] Brandstetter, etal (2006: 29).

[39] Brehm, Vicky Mancuso (2001) Promoting effective North South NGO Partnerships: A comparative Study of 10 European NGOs', INTRAC: The International NGO Training and Research Centre Occasional Papers Series, Number 35. http://dspace.africaportal.org/jspui/bitstream/123456789/2178 4/1/Promoting\%20Effective\%20North\%20South\%20NGO $\% 2$ 0Partnerships.pdf

[40] Brehm, Vicky, (2001b) NGO and partnerships. NGO Policy Briefing Paper No. 4, April. Oxford, UK. International NGO Training and Research Centre (INTRAC) http://www.intrac.org.

[41] Baulderstone, J., Presser, K. and Smith, M. (2008) 'Making three into one: the story of a merger in response to environmental change', Third Sector Review, vol. 14, no. 1: 67-81.

[42] Brehm, (2001).

[43] Kukundakwe, et al (2013).

[44] Brehm, (2001).

[45] Anschütz Justine (1996) Community-Based Solid Waste Management and Water Supply Project WASTE, Nieuwehaven 201. 
[46] Willem Elbers and Lau Schulpen, (2011) Decision Making in Partnerships for Development: Explaining the influence of local partners. Quarterly Nonprofit and Voluntary Sector 40(5) 795- 812. Published by Sage publications. http://nvs.sagepub.com/content/40/5/795

[47] Allen Ruth (2011) Local partnership guide: A guide for partnering with civil society, business and government groups. www.mercycorps.org/sites/default/files/mclocalpartnershipsgu ide.pdf

[48] Brinkerhoff Jennifer, (2002) Partnership for International Development. Rhetoric or Results. London. Lynne Rienner, Boulder, Co.

[49] Brehm. V (2001).

[50] Mckinskey (2001).

[51] Allen, (2011) pg. 25.

[52] PEN (2007) Examining Government and CSO Collaborations in Kenya: A Study Of Selected Successful Case Stories: What Can We Learn?

http://www.akdn.org/publications/civil_society_kenya_cso.pdf.

[53] Ramanthan T. R, (1992) Institutional strengthening of local NGOs involved in forestry: A challenge for innovation. FAO. www.fao.org/docrep/u7760e/u7760e0a.htm

[54] McManus Sue \& Ros Tennyson (2008) Talking the Walk: A Communication Manual for Partnership Practitioners. www.ThePartneringInitiative.org

[55] Audit commission (1998).

[56] Batti Rehema C, (2016) A Quest for Excellence: Building High Performance NGOs North Charleston, SC: CreateSpace.

[57] Hoksbergen, Roland. (2005). Building Civil Society through Partnership: Lessons from a Case Study of the Christian Reformed World Relief Committee. Development in Practice 15(1): 16-27.

http://policy-practice.oxfam.org.uk/publications/building-civil -society-through-partnership-lessons-from-a-case-study-of-the -chr-130696

[58] Hoksbergen, 2005.

[59] Spekman, Isabella \& MacAvoy (2000).

[60] Ashman (2001).

[61] Tennyson Ros, (2011) Partnering tool-book. The Partnering Initiative International Business Leaders Forum.

[62] Brehm, (2001).

[63] Gibbs Christopher, Thomas Kuby \& Claudio Furno (1999) Non-Governmental Organizations in World bank supported projects. A review. The World Bank http://ieg.worldbank.org/Data/reports/ngo_book.pdf

[64] Austin James E. (2010) Collaboration Challenge: How Nonprofits and Businesses Succeed through Strategic Alliances. USA Jossey-Bass: Hoboken, NJ.

[65] Fowler, A. and McMahon, J, (2010) Self-Assessment of a Multi-Stakeholder Collaborative Process. Findings and Lessons from a Survey of a Consortium for the Enhanced Livelihoods in the Mandera Triangle (ELMT) and Enhanced Livelihoods in Southern Ethiopia (ELSE) Program 2007-2009. Consortium Survey Report.
[66] Squire Catherine, (2012) Partnerships and capacity building. A guide for small and diaspora NGOs.

http://www.intrac.org/data/files/resources/781/Partneship-and-C apacity-Building_A-Guide-for-Small-and-Diaspora-NGOs.pdf

[67] Johnson and Ludema (1997).

[68] Zedek and Radovich (2006).

[69] Rochlin Steve, Zedeck Simon and Mara, (2008) Governing collaboration..... Making Partnerships Accountable for Delivering Development unpan1.un.org/intradoc/groups/public/documents/.../unpan03 1987.pdf

[70] Allen (2011), Pg. 30.

[71] Brandstetter, etal, 2006.

[72] Spekman, Isabella \& MacAvoy (2000).

[73] Spekman, Isabella \& MacAvoy (2000).

[74] Compassion Capital Fund (CCF) \& Mark Publow, (2010) Partnerships: Frameworks for Working Together. Compassion Capital Fund National Resource Center.

http://strengtheningnonprofits.org/resources/guidebooks/Partn erships.pdf

[75] Stott Leda, (2011) The partnering with Governments: Building effective collaboration with the public sector in Africa. London. International business leaders' forum (BLF) \& GTZ

[76] Kukundakwe, et al (2013).

[77] Brehm, Vicky (2004) Autonomy or Dependence? Case Studies of North-South NGO Partnerships, INTRAC: http://www.intrac.org/resources.php?action $=$ resource\&id=319

[78] Batti Rehema C, (2015) Community based partnerships: Nurturing Strategic NGO collaboration. North Charleston, SC: CreateSpace.

[79] Brehm (2004).

[80] British Council, (2010) Building skills, building partnerships A review and evaluation of the wider impact of British Council facilitated international partnerships.

[81] Hudson Lucian (2009) The Enabling State: Collaborating for Success. www.fco.gov.uk/pdpublication Hudson L (2009: 31)

[82] Sterne, R., Heaney, D., \& Britton, B, (2009) The Partnership Toolbox. World Wildlife Fund. http://assets.wwf.org.uk/downloads/wwf_parthershiptoolboxar tweb.pdf

[83] Tennyson, (2011) Pg. 11.

[84] Brehm (2001).

[85] Tennyson, (2011) Pg. 13.

[86] Steenburgen and Ansari (2003) Pg. 25.

[87] Tennyson (2011) Pg. 29.

[88] Hauck Volker and Land Tony, (2000) Beyond the Partnership Rhetoric Reviewing: Experiences and Policy Considerations for Implementing, 'Genuine' Partnerships in North-South Cooperation. ECDPM Discussion Paper No. 20. http://ecdpm.org/wp-content/uploads/2013/10/DP-20-experien ces-implementing-partnerships-north-south-2000-.pdf 
[89] Mckinskey \& Company, (2001) Effective capacity building in non-profit organizations. Venture Philanthropy partners Inc. http://www.vppartners.org/sites/default/files/reports/full_rpt.p df.

[90] Bardin Luc, Raphael \& Guillaume, (2014) Strategic Partnering: Removing chance and deliver consistent success. Great Britain. Kogan Page Limited.

[91] IFC, (2007) Stakeholder engagement Washington. International Finance Corporation.
[92] McManus \& Tennyson (2008).

[93] Kittel Joe, (2012) Spiritual principles in strategic alliances. USA. (e-book).

[94] Squire, (2012).

[95] Steenburgen and Ansari (2003) Pg. 6.

[96] Mc Manus \& Tennyson (2008).

[97] Mc Manus \& Tennyson (2008). 